\title{
Role of imaging in lung transplantation evaluation
}

\author{
Alexander D. Calvert, Todd R. Hazelton \\ Department of Radiology, University of South Florida Morsani College of Medicine, Tampa, FL, USA \\ Contributions: (I) Conception and design: TR Hazelton; (II) Administrative support: None; (III) Provision of study materials or patients: TR \\ Hazelton; (IV) Collection and assembly of data: All authors; (V) Data analysis and interpretation: All authors; (VI) Manuscript writing: All authors; \\ (VII) Final approval of manuscript: All authors. \\ Correspondence to: Todd R. Hazelton, MD, MS. Department of Radiology, University of South Florida Morsani College of Medicine, South Tampa \\ Center for Advanced Healthcare, 2 Tampa General Circle, STC 6102, Tampa, FL 33606-3571, USA. Email: thazelto@health.usf.edu.
}

\begin{abstract}
Lung transplantation is an effective treatment for patients with end-stage pulmonary disease. Due to the myriad of complications that can occur in the post-operative period and long-term after discharge, imaging plays a crucial role in the diagnosis and management of these patients. On imaging, the time of onset is most helpful in differentiating reimplantation response from acute rejection during the post-operative period. Bacterial and fungal infections may occur at any time after transplant, although viral infections tend to present after the post-operative period. Imaging is also helpful in evaluating postoperative pleural as well as short and long term airway anastomotic pathologies. Imaging is also useful in evaluating longer term pulmonary complications such as bronchiolitis obliterans, recurrent disease, and restrictive allograft syndrome. The imaging features of these various important thoracic complications of lung transplantation will be reviewed.
\end{abstract}

Keywords: Lung transplantation; complications; computed tomography; chest radiography

Submitted Jul 30, 2019. Accepted for publication Aug 20, 2019.

doi: $10.21037 /$ jtd.2019.08.35

View this article at: http://dx.doi.org/10.21037/jtd.2019.08.35

\section{Introduction}

The first attempted human lung transplant was performed by Dr. James Hardy in 1963, with the patient succumbing to kidney failure 18 days after the procedure (1). Nearly two decades later, in 1981, Drs. Norman Shumway and Bruce Reitz from Stanford University performed three heart-lung transplants, two of which were successful (2). In 1983, under the direction of Dr. Joel Cooper, the Toronto Lung Transplant Group performed the first successful lung transplant for pulmonary fibrosis (3). Since the early days of this procedure, lung transplants have continued to improve and have become an effective treatment for patients with end-stage pulmonary disease. Today, common indications for lung transplantation include emphysema, idiopathic pulmonary fibrosis, cystic fibrosis, and primary pulmonary hypertension $(\mathrm{PPH})(4,5)$.

Single lung transplants are generally reserved for patients with idiopathic pulmonary fibrosis, $\mathrm{PPH}$, and selected patients with emphysema, specifically those of shorter stature and older age. Single lung transplants are performed using a generous posterolateral thoracotomy through the fifth intercostal space with anastomoses from posterior to anterior (bronchus, artery, and left atrium). Bilateral lung transplantation is mandatory for patients with cystic fibrosis and bronchiectasis from other causes, is generally performed on patients with emphysema, and occasionally in PPH. Surgical techniques for bilateral lung transplantation include transsternal bilateral thoracotomy "clamshell" incision, which provides excellent exposure to the hilar structures, mediastinum and both pleural spaces, and bilateral anterolateral thoracotomy, which prevents complication of sternal healing often associated with the clamshell incision. Although less common, median sternotomy can be used for bilateral lung transplantation as well (6). Heart-lung transplantation is usually reserved for the rare patient with combined end-stage cardiac 
Typical time course for pulmonary complications after lung transplantation

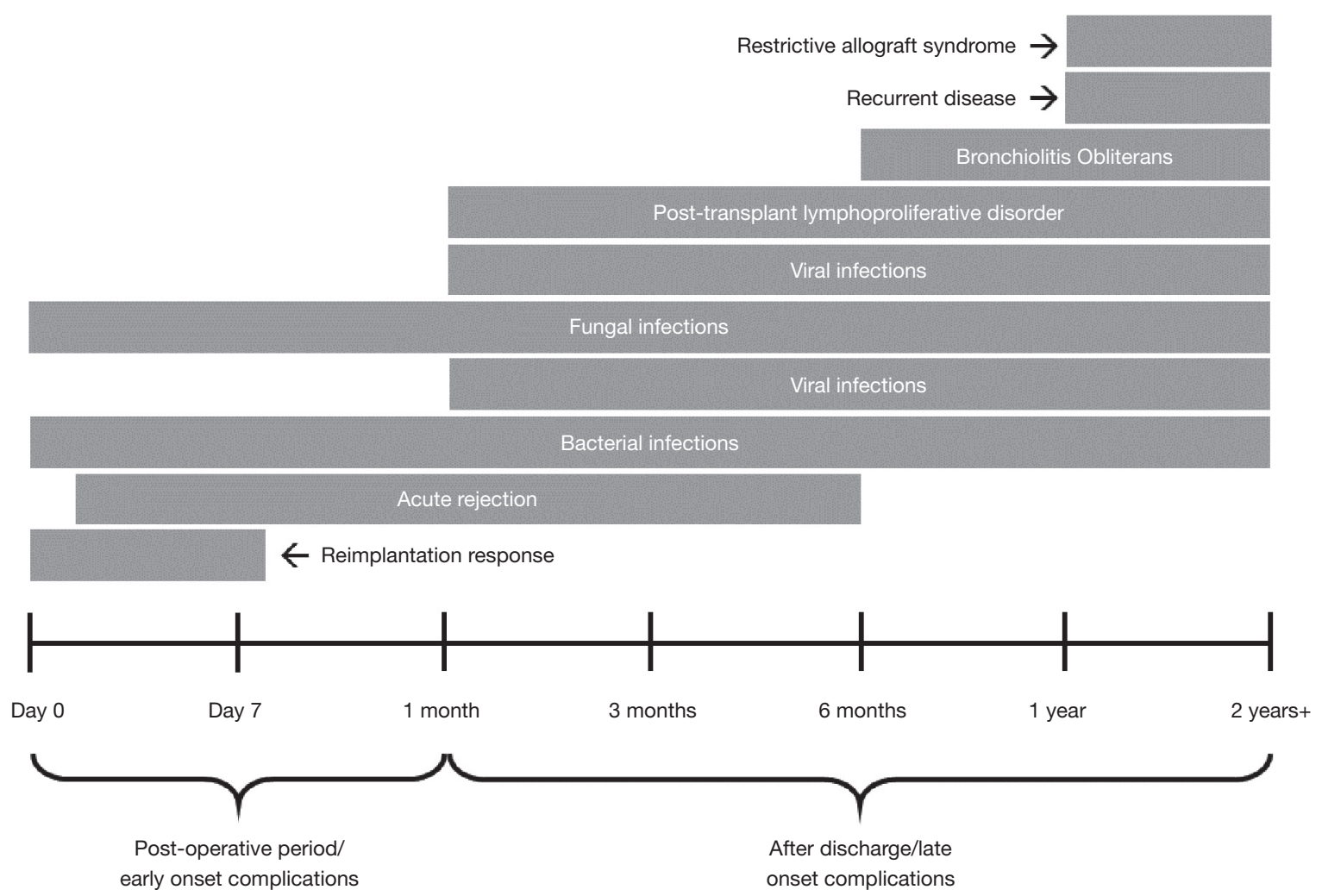

Figure 1 The typical time course for commonly encountered complications that occur after lung transplantation.

and pulmonary disease such as those with Eisenmenger's syndrome with $\mathrm{PPH}$ and significant left ventricular dysfunction (7).

Long-term survival following a lung transplant is lower than that of other types of solid organ transplantations due to a myriad of post-operative complications, which can be divided based on the temporal relationship to the operation. Imaging plays a crucial role in detecting such complications, and understanding certain radiographic features can help in identifying and addressing the complications promptly. In this report, we discuss the role of imaging in the lung transplant patient and describe the radiographic features of the most commonly encountered complications (Figure 1) in an effort to increase awareness for those physicians responsible for the imaging interpretation of these individuals.

\section{Pre-operative imaging for lung transplantation}

For lung transplant candidates, programs carefully evaluate donor lung size to optimize matching to a prospective recipient. Since there is generally no consensus on the definition of best "size" fit, some programs will use donor and recipient height values while taking into account recipient disease diagnosis. Other centers calculate donor and recipient total lung capacity (TLC) values and attempt to achieve as close a size match as possible (8). With regard to determining size compatibility, some sites will also incorporate radiographic measurements performed at set points on donor and recipient chest radiographs (Figure 2). Potential donors and recipients are ideally matched to within $10 \%$ of one another on each measurement (9).

In addition to size matching, imaging plays a role as one component in the overall assessment of a donor's lungs for transplantation. In a study by Alvarez et al., $12 \%$ of potential donors were deemed unsuitable for transplantation due to abnormal chest radiograph findings (10). The presence of consolidation or contusion on radiography may exclude the use of a potential donor's lungs (9). However, given the lack of available donor lungs and the subjectivity of chest 


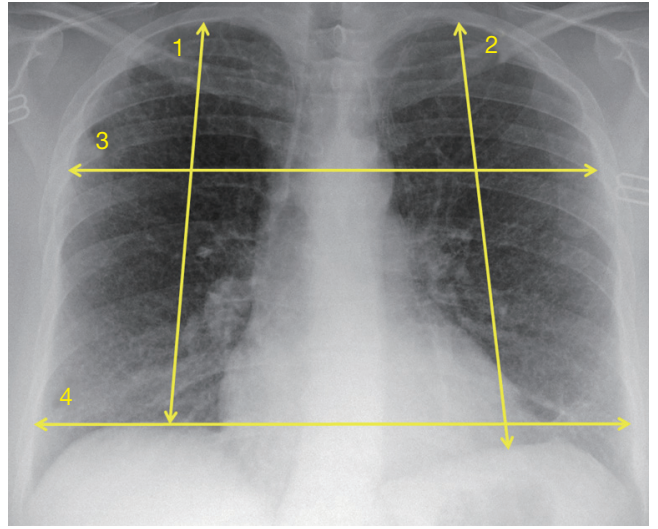

Figure 2 Example of lung measurements performed on donor and recipient chest radiographs to optimize matching using the technique reported by Bachus et al. (9). The lungs are measured from the dome of the right hemidiaphragm to the apex of the right lung [1], the dome of the left hemidiaphragm to the dome of the left lung [2], the width of both lungs together at the level of the aortic knob [3], and the width of both lungs together at the level of the higher hemidiaphragm [4].

radiograph interpretations, more objective clinical criteria related to age, smoking history, and pre-retrieval $\mathrm{PaO}_{2} / \mathrm{FiO}_{2}$ have been favored to expand the selection of donor lungs from outside the standard acceptability criteria (11).

\section{Imaging of early complications}

\section{Post-operative pulmonary complications}

Immediate post-operative complications of lung transplantation include reimplantation response, acute rejection, and infection. Reimplantation response, also known as reperfusion edema or primary graft dysfunction, is the most common postoperative complication (up to $95 \%$ of all patients) and is a form of noncardiogenic pulmonary edema. The transplanted lung undergoes an ischemic vascular injury resulting in increased capillary permeability and alveolar damage causing interstitial and alveolar edema. Usually occurring within several hours up to 48 hours following the procedure, reperfusion edema is treated with diuresis and mechanical support. The edema generally improves over 24 to 48 hours and resolves in 7 to 10 days (Figure 3). If there is persistence beyond the first week, infection or acute rejection should be considered. On imaging, there are perihilar and basilar airspace consolidations in the mid and lower lung zones with interstitial opacities and small pleural effusions (12).

In comparison to reimplantation response, acute rejection does not typically develop until 5 to 10 days following the procedure (Figure 4), and is very common as most patients have two to three significant rejection episodes in the first 3 months. Radiographs can be normal or appear similar to reimplantation response with possible reticular and/or ground glass opacities, consolidations, and indistinct 2-3 mm nodules visible on CT (Figure 5) (13). Distinguishing reimplantation response from acute rejection on imaging is best accomplished by the temporal relationship to the transplant procedure, but definitive diagnosis of acute rejection requires a transbronchial biopsy demonstrating a predominantly lymphocytic perivascular infiltrate (14). The rare exception is a hyperacute rejection, which is a rapidly fulminating syndrome that occurs within hours following the transplant and is likely due to the interaction of preformed recipient antibodies against major donor allograft antigens (15).

Early onset infection is the most common complication after transplantation and is a major cause of morbidity and mortality. Bacterial infections (Figure 6) predominate in the immediate post-operative period and represent at least half of all infections with the highest incidence in the first four weeks after transplantation (16,17). Viral infections are generally not seen until after four weeks whereas fungal infections can occur at any period. Radiographic and CT findings are similar to those of non-transplant patients and are unable to reliably distinguish between bacterial, viral and fungal etiologies (18).

Lung torsion is a rare early complication (Figure 7) that is predisposed to by differences in caliber between the recipient thoracic cavity and an overly small transplanted lung, which rapidly progresses to parenchymal necrosis if untreated (19,20). Torsion is diagnosed on CT angiography with torsion of the pulmonary artery and adjacent bronchi with distal obliteration and displacement of the hilum and fissures (19).

\section{Post-operative pleural complications}

Pleural complications are seen in $22-34 \%$ of patients after transplantation. Since bilateral lung and heart-lung transplantations frequently result in a single communicating pleural space, fluid and gas collections are often bilateral (Figure 8). Pleural effusions develop in almost all patients because of increased capillary permeability and impaired 

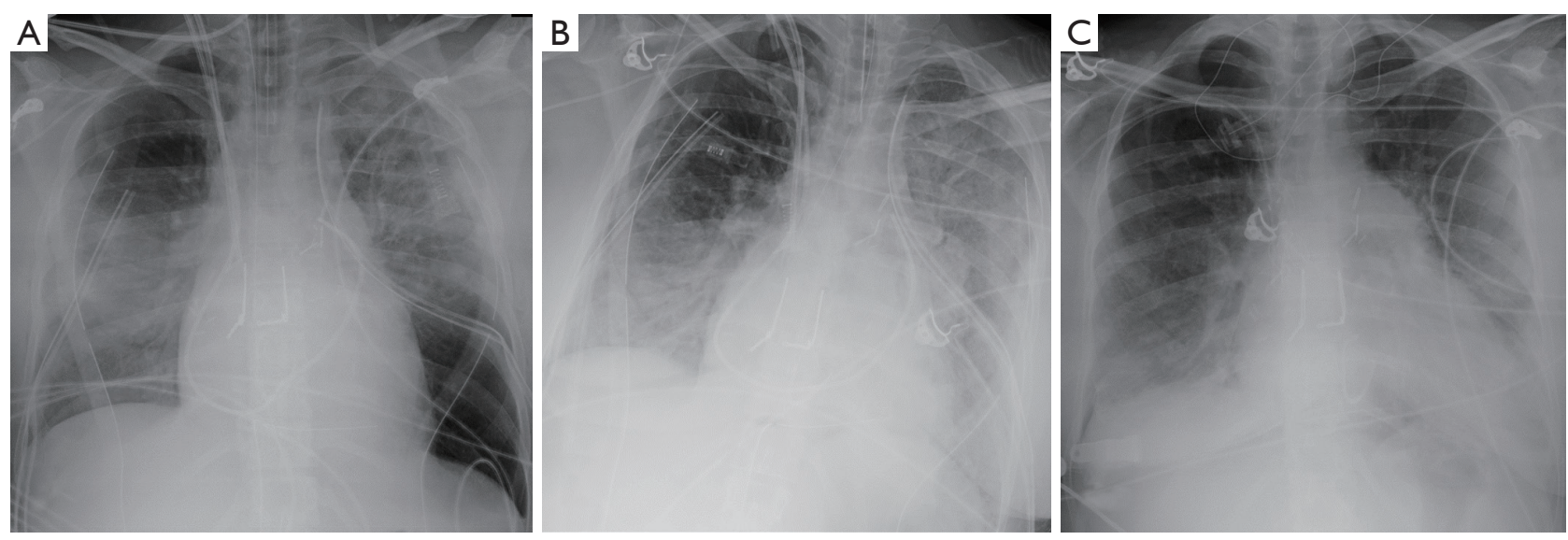

Figure 3 A series of AP chest radiographs obtained after bilateral lung transplantation demonstrate mild bilateral airspace consolidations on post-operative day 1 (A), worsening bilateral airspace consolidations on post-operative day 3 (B), and resolving airspace consolidations by post-operative day $8(\mathrm{C})$ consistent with reimplantation response, also known are reperfusion pulmonary edema or primary graft dysfunction. AP, anteroposterior.
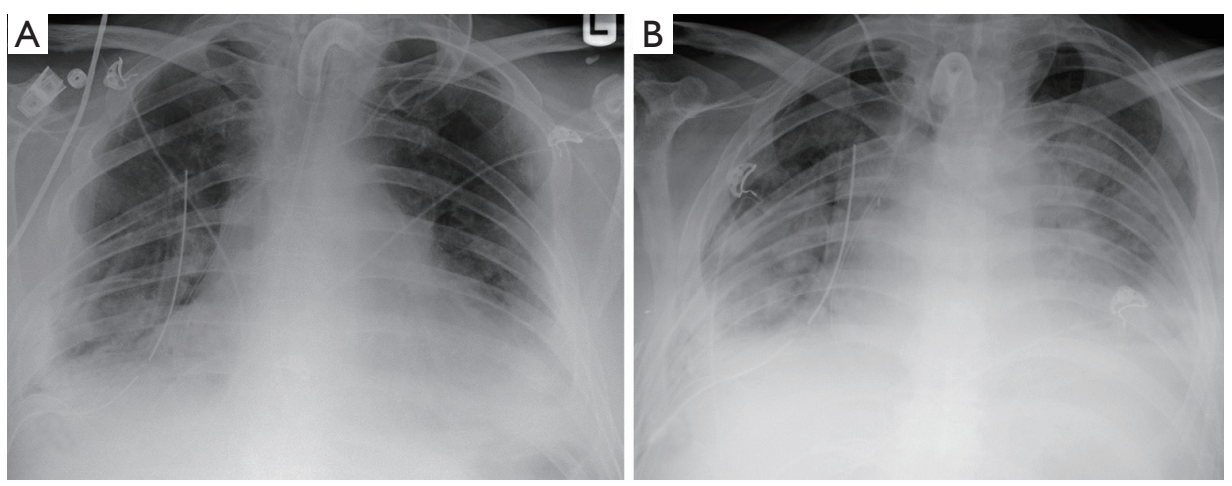

Figure $4 \mathrm{AP}$ chest radiograph series in a patient who has undergone bilateral lung transplantation shows bibasilar atelectasis on postoperative day 15 (A) and increased bilateral lung airspace consolidations by post-operative day 30 (B) consistent with acute rejection. AP, anteroposterior.
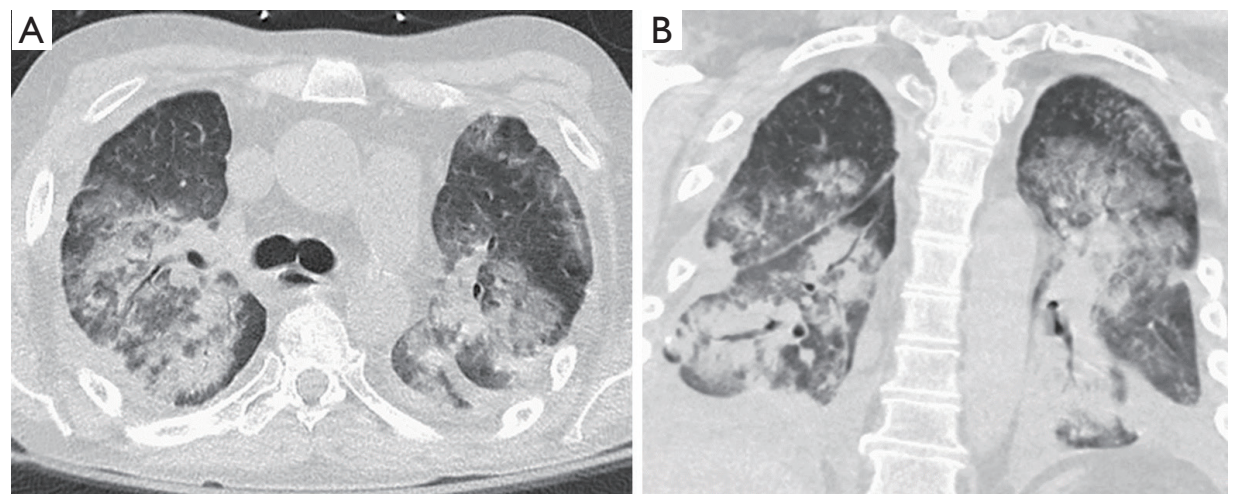

Figure 5 Axial (A) and coronal (B) CT images of a 48-year-old male 2 years post bilateral lung transplant with antibody-mediated rejection shows bilateral lung peribronchovascular consolidations and ground glass opacifications. 

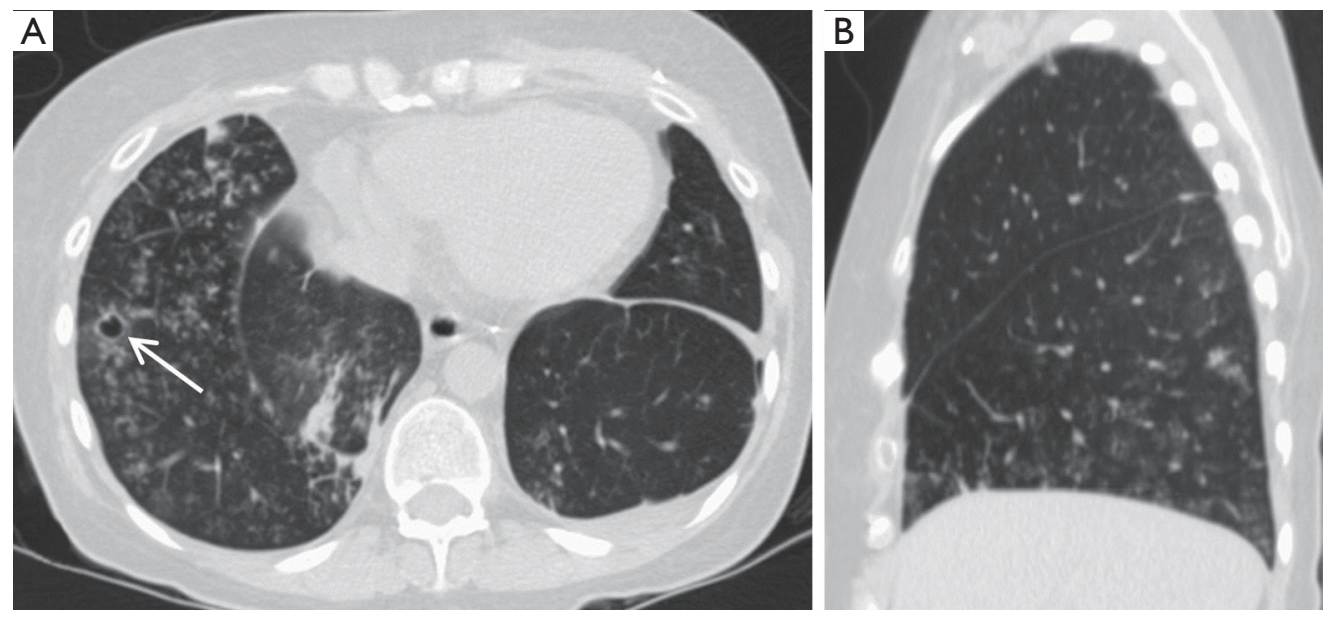

Figure 6 Axial (A) and sagittal (B) images of a patient post bilateral lung transplant with Staphylococcus aureus pneumonia shows lower lung predominant tree-in-bud nodules as well as a small thin-walled cavity (white arrow) in the right lower lobe.
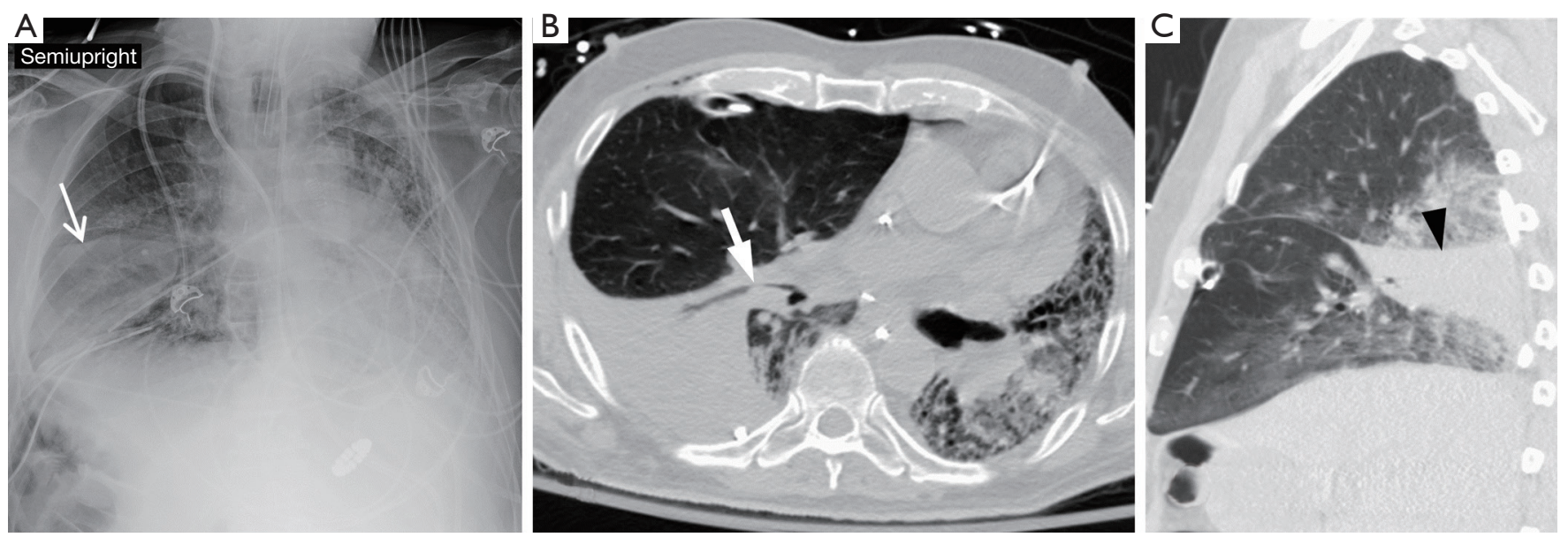

Figure 7 Post-operative AP chest radiograph (A) in a patient who underwent right lung transplantation for idiopathic pulmonary fibrosis. Due to hemodynamic instability in the operating room, left lung transplantation was abandoned. The radiograph shows an abnormal triangular shaped opacification in the right lower lung (white arrow). Axial (B) and sagittal (C) CT images in this patient show abnormal position of the right middle lobe posteriorly within the right hemithorax (black arrowhead) as well as abnormal posterior displacement and narrowing of the right middle lobe bronchus (closed white arrow) consistent with right middle lobe torsion.

lymphatic clearance, and typically resolve within 2 weeks. Persistent or delayed effusions suggest complicated effusions such as empyema (Figure 9), organized hematoma (Figure 10), rejection, and post-transplantation lymphoproliferative disorder. A pneumothorax is the most common pleural complication that typically resolves with the insertion of a thoracostomy tube. If there are new, persistent, or enlarging pneumothoraces, there should be further evaluation to determine the cause of the air leak. Empyemas occur in approximately $4 \%$ of patients and are the only pleural complication associated with an increased mortality rate. Empyemas may affect both hemithoraces and should be excluded in the presence of a new or enlarging pleural effusion (21).

\section{Post-operative airway complications}

Dehiscence is an early airway anastomotic complication 

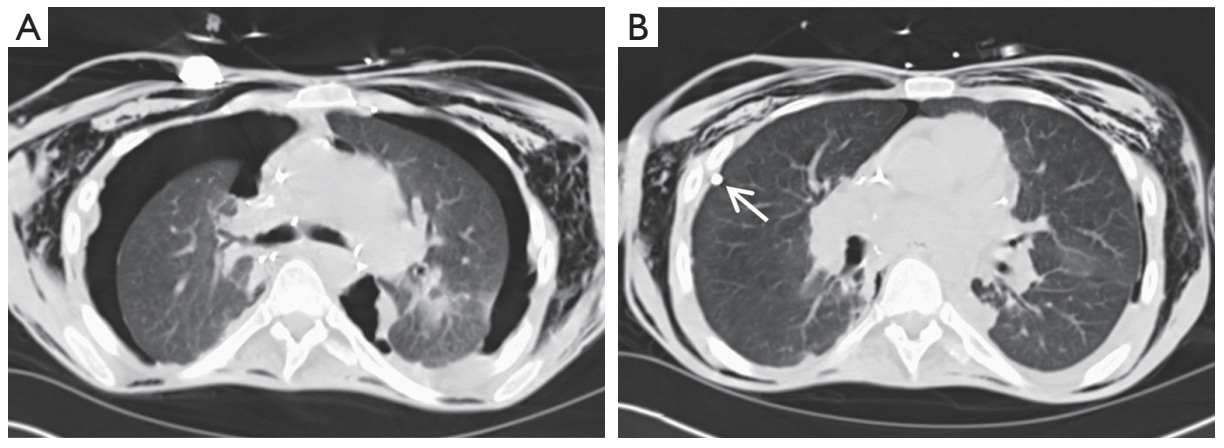

Figure 8 Axial CT images of the chest in a patient post bilateral lung transplant done using transverse sternotomy and clamshell incision show bilateral pneumothoraces due to continuity between the right and left pleural spaces (A). After insertion of a single pleural catheter on the right (white arrow), both pneumothoraces have significantly decreased in size (B).
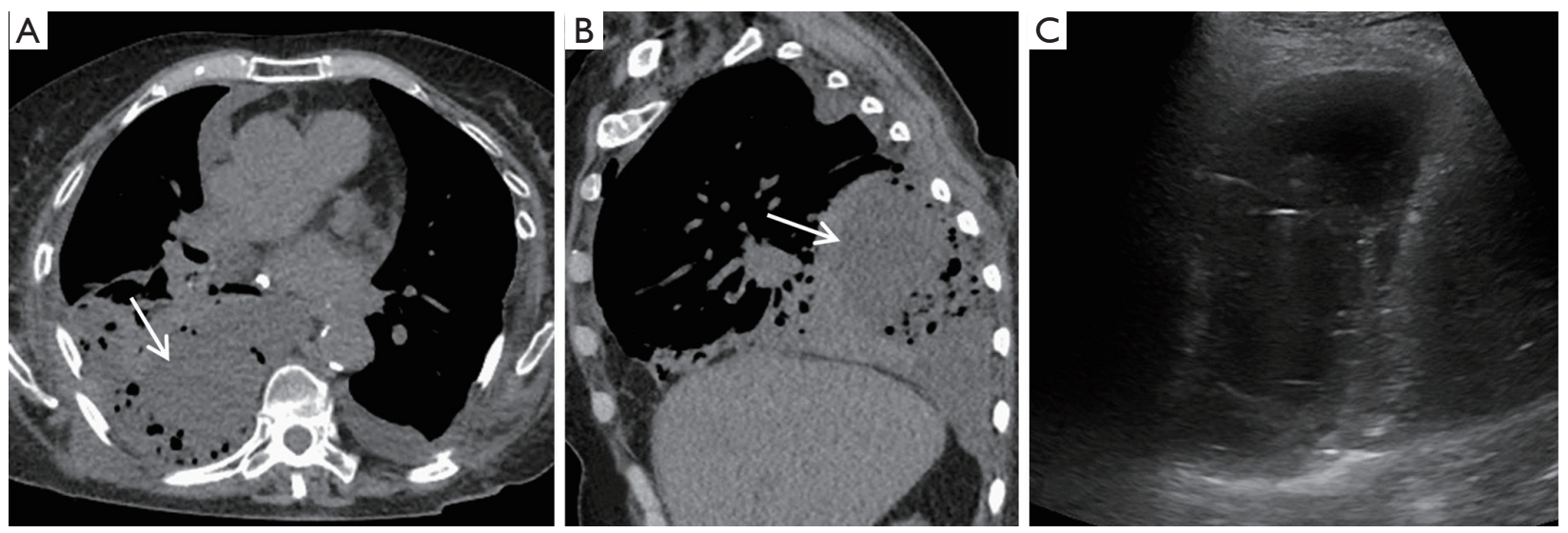

Figure 9 Axial (A) and sagittal (B) CT images of the chest in a patient with right upper quadrant pain post bilateral lung transplantation 5 weeks ago shows a loculated gas and fluid collection within the posteroinferior right pleural space (white arrows) consistent with empyema. Ultrasound image of the chest done before insertion of a pleural catheter demonstrates areas of loculation within the empyema (C).
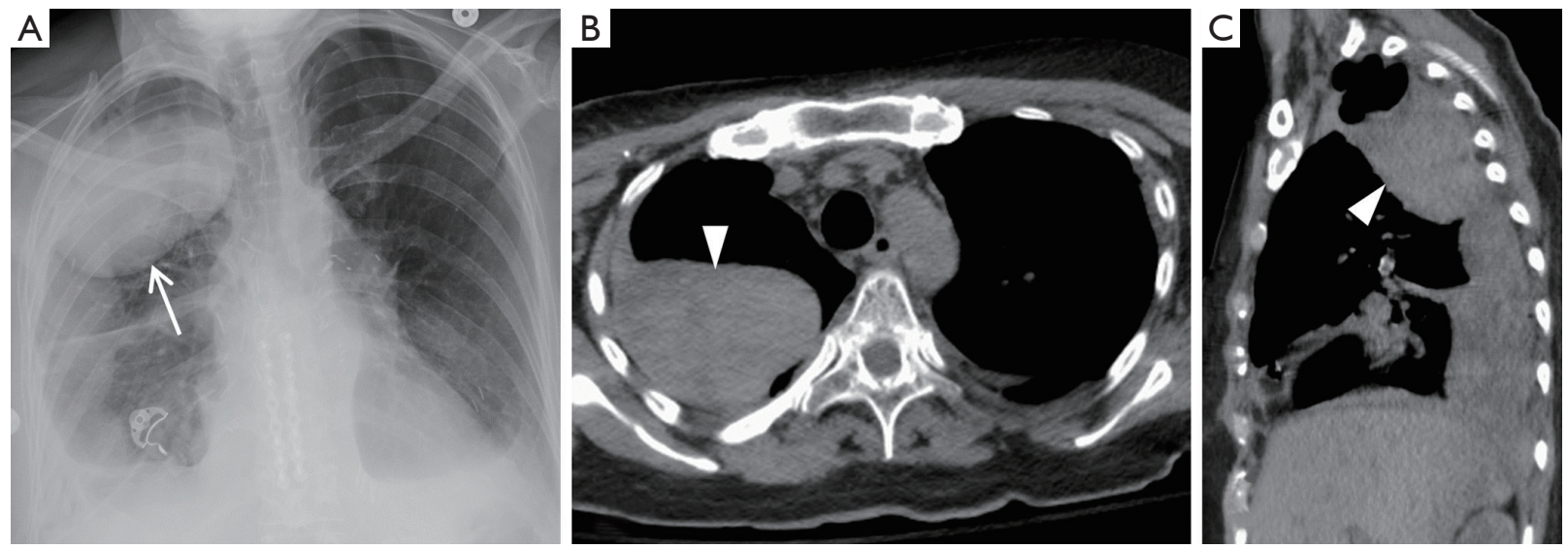

Figure 10 AP chest radiograph (A) of a 48-year-old female post-operative day 1 from bilateral lung transplantation shows right apical pleural based opacity (white arrow) which appears heterogeneous and high attenuation in the posterosuperior right pleural space on axial (B) and sagittal (C) CT images (white arrowheads), consistent with a post-operative hemothorax. 

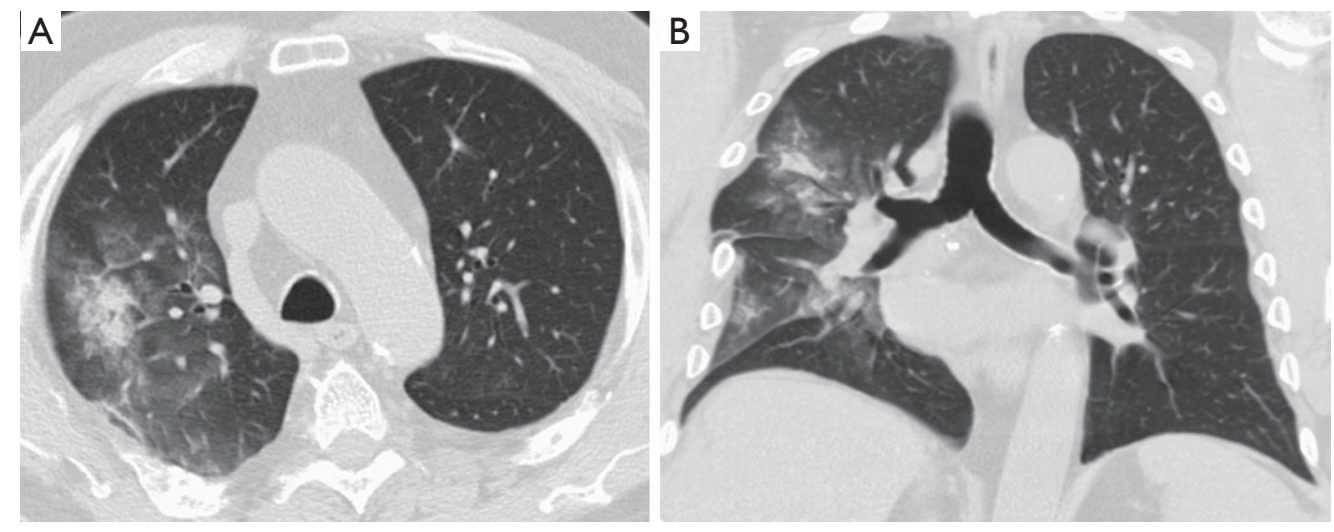

Figure 11 Axial (A) and coronal (B) CT images of a bilateral lung transplant patient with respiratory syncytial virus (RSV) pneumonia shows right upper and middle lobe peribronchiolar nodular consolidations and ground glass opacifications.

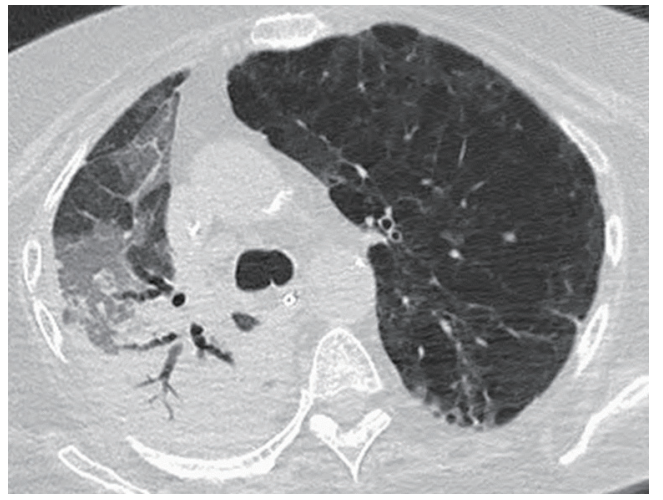

Figure 12 Axial CT image in a patient post right lung transplant with aspergillus pneumonia shows confluent consolidation and ground glass opacification in the transplanted lung.

( $<1$ month) that is difficult to treat and has a high mortality. Partial dehiscence is more common than complete dehiscence and presents as an enlarging ipsilateral pneumothorax or pneumomediastinum. On CT, dehiscence appears as a mucosal irregularity or soft tissue debris at the anastomosis with extraluminal air directly connected to the airway and irregular pockets of air posterior to the anastomosis. These findings are important to distinguish from normal postoperative findings, which can include a small amount of extraluminal air without a focal wall defect. Additionally, a telescoping bronchus may mimic dehiscence if the telescoped segment appears as a bronchial wall defect with a soft tissue irregularity or small tubular extraluminal gas collection (22).

\section{Imaging of long term complications}

\section{Infections}

Whereas bacterial infections predominate in the first month, viral infections are more frequent between 1-6 months after transplantation with cytomegalovirus (CMV) being the most common cause (almost 50\%). Additional viral organisms include influenza, parainfluenza, respiratory syncytial virus (RSV), and adenovirus. About half of all cases appear essentially normal on radiographs with the remainder demonstrating nonspecific heterogeneous opacities. On CT, viral pneumonia will appear as ground glass opacities, diffuse micronodules (tree-in-bud), bronchiectasis and diffuse consolidation (Figure 11) (23). Fungal infections can occur at any time and can commonly be involved with either a tracheobronchitis or an anastomotic infection. Aspergillus infections, in particular, can include both anastomotic dehiscence and stenosis. Invasive pulmonary infections and disseminated disease are less frequent with an overall mortality of approximately $50 \%$. The primary manifestations of fungal pneumonia include nodules and focal consolidations (Figures 12,13). Cavitation may also occur with fungal pneumonias (Figure 14). On CT, invasive aspergillosis can demonstrate focal parenchymal opacification surrounded by a ground glass halo, which represents alveolar hemorrhage at the periphery $(19,23)$.

\section{Post-transplant lymphoproliferative disorder (PTLD)}

PTLD is a spectrum of diseases that vary from histologically 

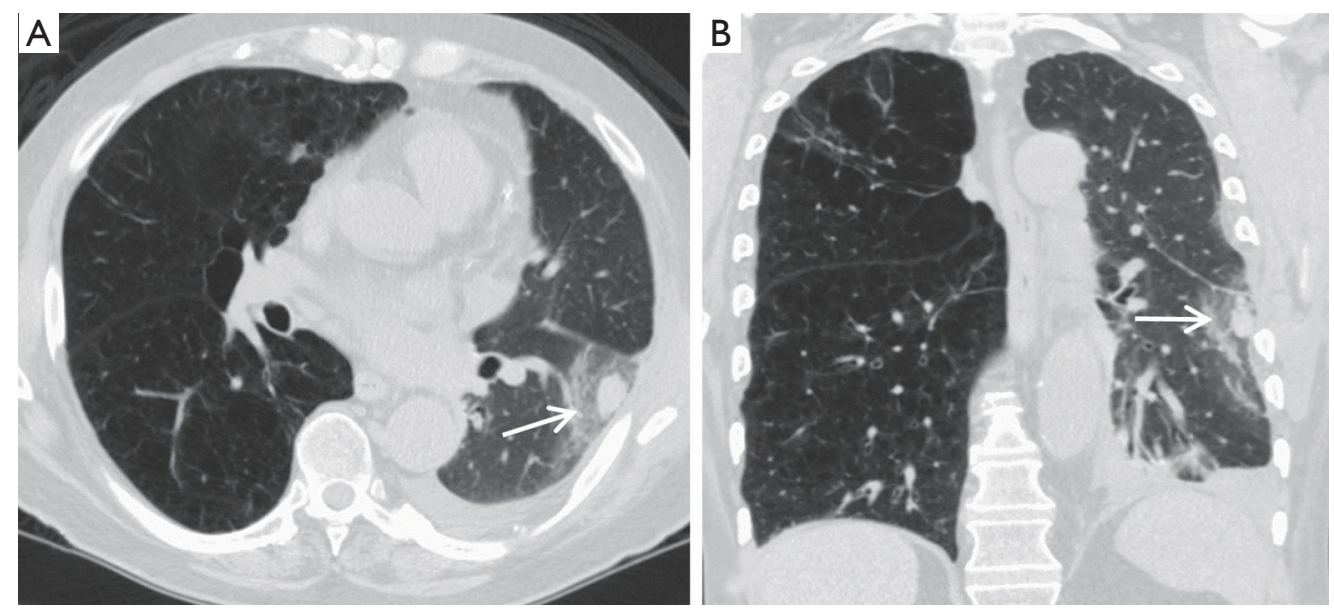

Figure 13 Axial (A) and coronal (B) CT images of a patient post left lung transplant with aspergillus infection manifesting as a left lower lobe nodule surrounded by a ground glass "halo" (white arrow).

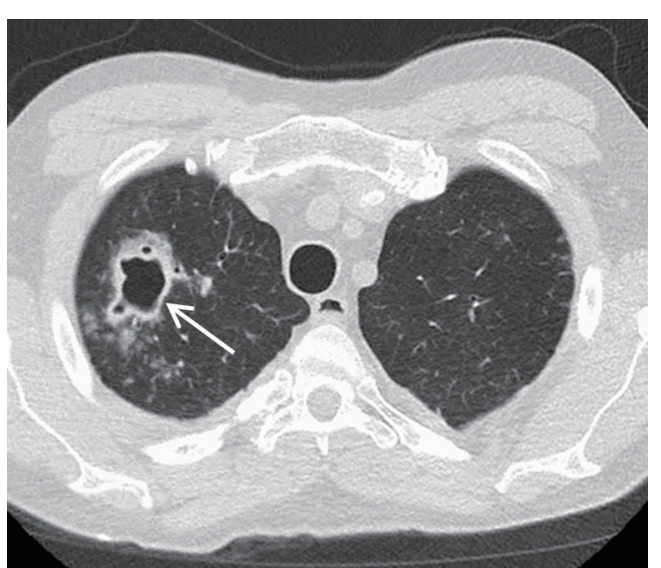

Figure 14 Axial CT image of the lungs in a patient with Nocardia pneumonia post bilateral lung transplantation. This bacterial infection can masquerade as a fungal pneumonia and shows clustered small right upper lobe nodules and an irregularly marginated cavity (white arrow).

benign polyclonal lymphoid proliferation to an aggressive high-grade lymphoma. Major risk factors include immunosuppression with cyclosporine and a history of Epstein-Barr virus (EBV) (24,25). The underlying etiology is thought to be from a B-cell lymphocyte proliferation in response to an EBV infection, typically an EBVseronegative recipient who receives a seropositive donor lung $(26,27)$. The disorder may manifest from 1 month to several years after transplantation and typically peaks around
3-4 months with an overall prevalence of $1 \%$ to $10 \%$ (13). Compared to other solid organ transplants, PTLD occurs most frequently in lung transplantations. On imaging, pulmonary involvement is demonstrated by solitary or multiple pulmonary nodules or masses with parenchymal consolidation $(28,29)$. Extrapulmonary involvement can manifest as hilar or mediastinal lymphadenopathy, thymic enlargement, pleural effusions, or pericardial masses $(26,27)$.

\section{Bronchiolitis obliterans syndrome}

Chronic rejection is rare before 6 months following transplant but can affect up to $60 \%$ of recipients after 5 years and is the leading cause of long-term death $(30,31)$. There is a higher risk of chronic rejection if the patient has a history of an acute rejection (32). Bronchiolitis obliterans syndrome is manifestation of chronic rejection, with a mean onset of 6 to 12 months, which presents with a combination of increased dyspnea, productive cough, and progressive fall in FEV1. Patients are at a higher risk if they have 3 or more acute rejection episodes in the first 6 months or develop CMV pneumonia $(33,34)$. Radiographs often appear normal but hyperinflation, reduction in peripheral vascularity, and bronchiectasis may be seen. On CT, a mosaic attenuation pattern is seen on inspiration and air trapping on expiration (Figure 15). Additional findings may include bronchiectasis, bronchial wall thickening, and small nodular and linear branching opacities in a bronchiolar distribution $(17,35)$. 


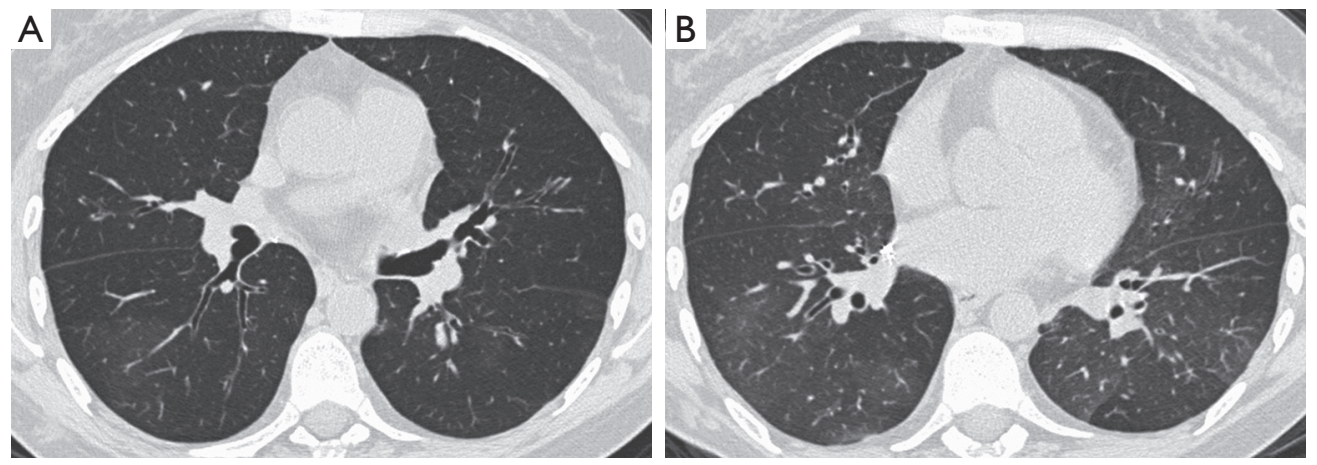

Figure 15 Axial inspiratory high resolution CT of the chest (A) in a patient with bronchiolitis obliterans syndrome after bilateral lung transplantation shows mild mosaic attenuation pattern with geographic areas of normal and decreased lung attenuation. On expiratory high resolution CT, geographic areas of air trapping are present in both lungs (B).
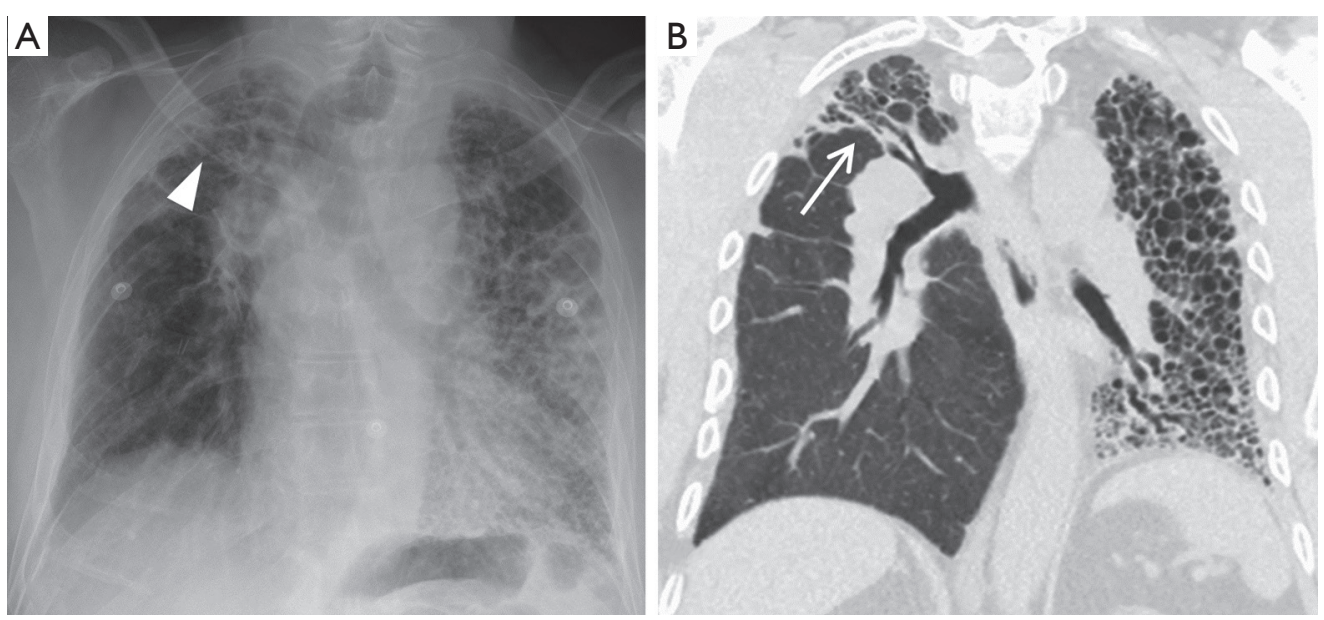

Figure 16 PA chest radiograph (A) in a patient post right lung transplantation 11 years ago for idiopathic pulmonary fibrosis demonstrates right upper lobe volume loss and reticulation (white arrowhead). On coronal CT (B), there is right upper lobe volume loss, reticulation, and traction bronchiectasis (white arrow) consistent with restrictive allograft syndrome. A small volume native left lung demonstrates extensive honeycombing consistent with clinical diagnosis of idiopathic pulmonary fibrosis. PA, posteroanterior.

\section{Restrictive allograft syndrome}

Restrictive allograft syndrome is a rare form of chronic lung allograft dysfunction consisting of restrictive functional changes involving peripheral lung pathology, which develops 1 to 4 years after transplant. CT findings include interlobar septal thickening, honeycombing, intralobular interstitial thickening, traction bronchiectasis, architectural distortion and volume loss (Figure 16). There also may be progressive upper lobe fibrosis, diffuse fibrosis across multiple lobes, or fibrosis limited to lower lobes $(36,37)$.

\section{Airway anastomotic strictures}

Bronchial stenosis is the most frequently reported longterm airway complication, which may result in recurrent lobar collapse and post-obstructive pneumonia. Bronchial stenosis often develops as a sequela of early complications such as ischemia, granulation tissue, fistula, and infection. Diagnosis of significant stenosis is made on CT with focal airway narrowing $>70 \%$ that does not change with inspiration or expiration. Virtual bronchoscopy, multiplanar images, and minimum projection images are often helpful 

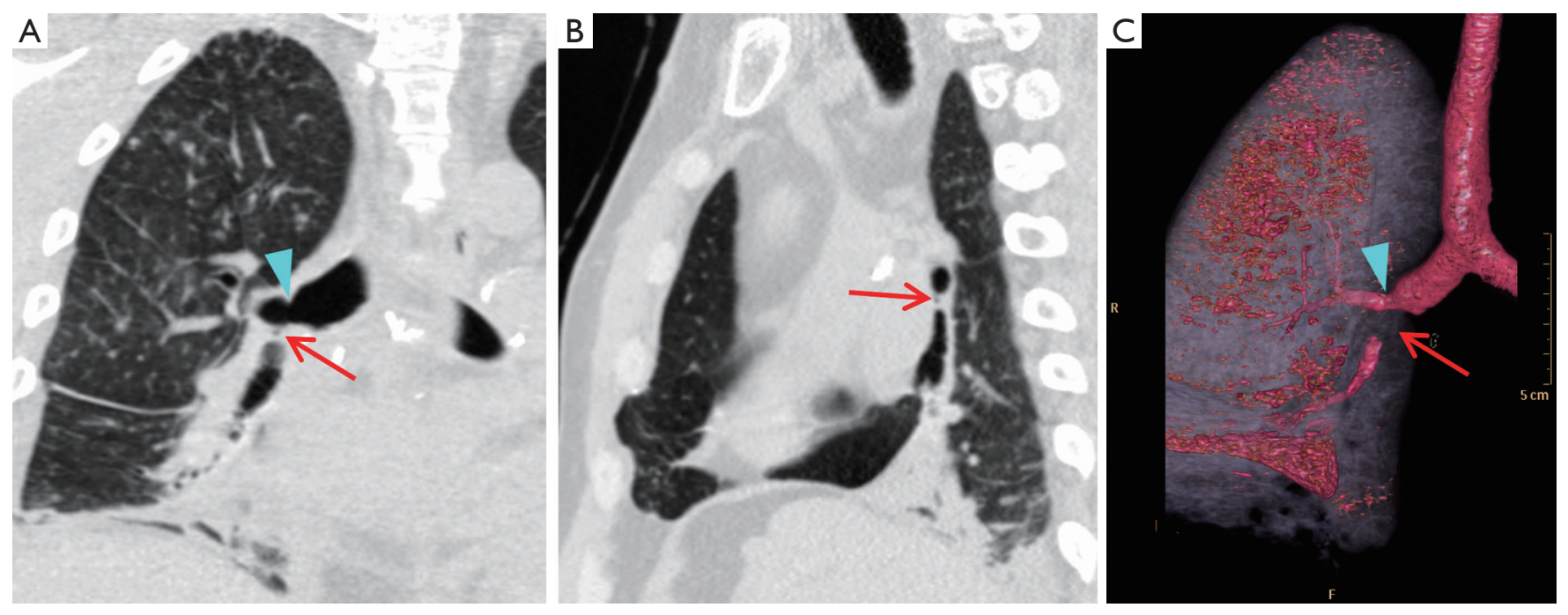

Figure 17 Coronal (A) and sagittal (B) CT images as well as 3D reconstruction image (C) of the right lung show focal narrowing of the anastomosis of the transplanted right lung to the native right main bronchus (cyan arrowhead) with segmental stenosis also involving proximal bronchus intermedius (red arrow).

to localize and diagnose airway strictures (Figure 17) (22).

\section{Recurrent lung disease}

Recurrent disease in a lung allograft is also a long-term concern with radiologic features similar to those of the original disease although findings can mimic other posttransplantation complications. The most common disease to reoccur is sarcoidosis followed by Langerhans cell histiocytosis and lymphangioleiomyomatosis (LAM) (33).

\section{Conclusions}

In summary, imaging plays a critical role in the diagnosis of early (post-operative) and late (after discharge) complications of lung transplantation. Providers should be familiar with basic surgical techniques and the imaging appearance of common complications. Since the radiologic pattern of disease can be nonspecific, it is important to appreciate the time course from lung transplantation as well as any relevant postoperative history.

\section{Acknowledgments}

Funding: None.

\section{Footnote}

Provenance and Peer Review: This article was commissioned by the Guest Editor (Ammar Chaudhry) for the series "Role of Precision Imaging in Thoracic Disease" published in Fournal of Thoracic Disease. The article was sent for external peer review organized by the Guest Editor and the editorial office.

Conflicts of Interest: Both authors have completed the ICMJE uniform disclosure form (available at http://dx.doi. org/10.21037/jtd.2019.08.35). The series "Role of Precision Imaging in Thoracic Disease" was commissioned by the editorial office without any funding or sponsorship. The authors have no other conflicts of interest to declare.

Ethical Statement: The authors are accountable for all aspects of the work in ensuring that questions related to the accuracy or integrity of any part of the work are appropriately investigated and resolved.

Open Access Statement: This is an Open Access article distributed in accordance with the Creative Commons Attribution-NonCommercial-NoDerivs 4.0 International License (CC BY-NC-ND 4.0), which permits the non- 
commercial replication and distribution of the article with the strict proviso that no changes or edits are made and the original work is properly cited (including links to both the formal publication through the relevant DOI and the license). See: https://creativecommons.org/licenses/by-nc-nd/4.0/.

\section{References}

1. Lynch JP, Ross DJ. Lung and heart-lung transplantation. Lung biology in health and disease, vol 217. New York: Taylor \& Francis, 2006.

2. Reitz BA. The first successful combined heart-lung transplantation. J Thorac Cardiovasc Surg 2011;141:867-9.

3. Toronto Lung Transplant Group. Unilateral lung transplantation for pulmonary fibrosis. N Engl J Med 1986;314:1140-5.

4. International guidelines for the selection of lung transplant candidates. The American Society for Transplant Physicians (ASTP)/American Thoracic Society (ATS)/ European Respiratory Society (ERS)/International Society for Heart and Lung Transplantation (ISHLT). Am J Respir Crit Care Med 1998;158:335-9.

5. Orens JB, Estenne M, Arcasoy S, et al. International guidelines for the selection of lung transplant candidates: 2006 update--a consensus report from the Pulmonary Scientific Council of the International Society for Heart and Lung Transplantation. J Heart Lung Transplant 2006;25:745-55.

6. Dark JH. Median Sternotomy for Lung Transplantation. Operative Techniques in Thoracic and Cardiovascular Surgery 2015;20:87-103.

7. Sugarbaker DJ. Adult chest surgery. New York: McGrawHill Companies, 2009.

8. Mason DP, Batizy LH, Wu J, et al. Matching donor to recipient in lung transplantation: How much does size matter? J Thorac Cardiovasc Surg 2009;137:1234-1240.e1.

9. Backhus LM, Mulligan MS, Ha R, et al. Imaging in Lung Transplantation: Surgical Considerations of Donor and Recipient. Radiol Clin North Am 2016;54:339-53.

10. Alvarez A, Moreno P, Espinosa D, et al. Assessment of lungs for transplantation: a stepwise analysis of 476 donors. Eur J Cardiothorac Surg 2010;37:432-9.

11. Zych B, Garcia Saez D, Sabashnikov A, et al. Lung transplantation from donors outside standard acceptability criteria--are they really marginal? Transpl Int 2014;27:1183-91.

12. Kundu S, Herman SJ, Winton TL. Reperfusion edema after lung transplantation: radiographic manifestations.
Radiology 1998;206:75-80.

13. Garg K, Zamora MR, Tuder R, et al. Lung transplantation: indications, donor and recipient selection, and imaging of complications. Radiographics 1996;16:355-67.

14. Engeler CE. Heart-lung and lung transplantation. Radiol Clin North Am 1995;33:559-80.

15. Diez Martinez P, Pakkal M, Prenovault J, et al. Postoperative imaging after lung transplantation. Clin Imaging 2013;37:617-23.

16. de Perrot M, Chaparro C, McRae K, et al. Twenty-year experience of lung transplantation at a single center: Influence of recipient diagnosis on long-term survival. J Thorac Cardiovasc Surg 2004;127:1493-501.

17. Ng YL, Paul N, Patsios D, et al. Imaging of lung transplantation: review. AJR Am J Roentgenol 2009;192:S1-13, quiz S14-9.

18. Collins J, Muller NL, Kazerooni EA, et al. CT findings of pneumonia after lung transplantation. AJR Am J Roentgenol 2000;175:811-8.

19. Hemmert C, Ohana M, Jeung MY, et al. Imaging of lung transplant complications. Diagn Interv Imaging 2014;95:399-409.

20. Isnard J, Trogrlic S, Haloun A, et al. [Heart and heart-lung transplants thorax complications: major radiologic forms]. J Radiol 2007;88:339-48.

21. Herridge MS, de Hoyos AL, Chaparro C, et al. Pleural complications in lung transplant recipients. J Thorac Cardiovasc Surg 1995;110:22-6.

22. Luecke K, Trujillo C, Ford J, et al. Anastomotic Airway Complications After Lung Transplant: Clinical, Bronchoscopic and CT Correlation. J Thorac Imaging 2016;31:W62-71.

23. Krishnam MS, Suh RD, Tomasian A, et al. Postoperative complications of lung transplantation: radiologic findings along a time continuum. Radiographics 2007;27:957-74.

24. Montone KT, Litzky LA, Wurster A, et al. Analysis of Epstein-Barr virus-associated posttransplantation lymphoproliferative disorder after lung transplantation. Surgery 1996;119:544-51.

25. Rappaport DC, Weisbrod GL, Herman SJ. Cyclosporineinduced lymphoma following a unilateral lung transplant. The Toronto Lung Transplant Group. Can Assoc Radiol J 1989;40:110-1.

26. Murray JG, McAdams HP, Erasmus JJ, et al. Complications of lung transplantation: radiologic findings. AJR Am J Roentgenol 1996;166:1405-11.

27. Reams BD, McAdams HP, Howell DN, et al. Posttransplant lymphoproliferative disorder: incidence, 
presentation, and response to treatment in lung transplant recipients. Chest 2003;124:1242-9.

28. Collins J, Muller NL, Leung AN, et al. Epstein-Barrvirus-associated lymphoproliferative disease of the lung: CT and histologic findings. Radiology 1998;208:749-59.

29. Dodd GD, 3rd, Ledesma-Medina J, Baron RL, et al. Posttransplant lymphoproliferative disorder: intrathoracic manifestations. Radiology 1992;184:65-9.

30. Bankier AA, Van Muylem A, Knoop C, et al. Bronchiolitis obliterans syndrome in heart-lung transplant recipients: diagnosis with expiratory CT. Radiology 2001;218:533-9.

31. Chabot F, Vial B, Siat J, et al. Lung transplantation: indications, techniques and results. Rev Pneumol Clin 2000;56:301-12.

32. Knoop C, Estenne M. Acute and chronic rejection after lung transplantation. Semin Respir Crit Care Med 2006;27:521-33.

Cite this article as: Calvert $\mathrm{AD}$, Hazelton TR. Role of imaging in lung transplantation evaluation. J Thorac Dis 2020;12(9):51475158. doi: $10.21037 /$ jtd.2019.08.35
33. Collins J. Imaging of the chest after lung transplantation. J Thorac Imaging 2002;17:102-12.

34. Sharples LD, Tamm M, McNeil K, et al. Development of bronchiolitis obliterans syndrome in recipients of heartlung transplantation--early risk factors. Transplantation 1996;61:560-6.

35. Worthy SA, Park CS, Kim JS, et al. Bronchiolitis obliterans after lung transplantation: high-resolution CT findings in 15 patients. AJR Am J Roentgenol 1997;169:673-7.

36. Konen E, Weisbrod GL, Pakhale S, et al. Fibrosis of the upper lobes: a newly identified late-onset complication after lung transplantation? AJR Am J Roentgenol 2003;181:1539-43.

37. Sato M, Waddell TK, Wagnetz U, et al. Restrictive allograft syndrome (RAS): a novel form of chronic lung allograft dysfunction. J Heart Lung Transplant 2011;30:735-42. 